\title{
OBJEÇÕES DA PROCESSUALIDADE DEMOCRÁTICA AO MINIMALISMO \\ JUDICIAL: UM ESTUDO CRÍTICO À LUZ DA TEORIA NEOINSTITUCIONALISTA DO PROCESSO ${ }^{1}$
}

\section{OBJECTIONS OF DEMOCRATIC PROCEDURAL LAW TO JUDICIAL MINIMALISM: A CRITICAL STUDY IN THE LIGHT OF THE NEOINSTITUTIONALIST PROCEDURAL THEORY}

Bruno Paiva Bernardes

Doutorando em Teoria do Direito e da Justiça pelo Programa de Pós-Graduação em Direito da Pontifícia Universidade Católica de Minas Gerais. Mestre em Direito Público pela Universidade FUMEC, tendo sido bolsista da Fundação de Amparo à Pesquisa de Minas Gerais (FAPEMIG). Pós-Graduado em Filosofia e Teoria do Direito pela PUC Minas. Pós-Graduado em Direito Processual pela UNISUL. Belo Horizonte/MG. Orcid: https://orcid.org/0000-0003-0340-0328. E-mail: contato@professorbrunobernardes.com.br.

RESUMO: O presente artigo questiona, como problema de pesquisa, a compatibilidade democrática do minimalismo judicial de Cass Sunstein à luz da teoria neoinstitucionalista do processo, elaborada por Rosemiro Pereira Leal a partir de forte matriz popperiana, e adotada como marco teórico principal para as objeções à concepção de Sunstein neste escrito. Desse modo, o objetivo geral do artigo é contrapor as principais bases do minimalismo judicial de Sunstein à processualidade democrática preconizada pela teoria neoinstitucionalista. Como hipótese, afirma-se que o antagonismo existente entre, de um lado, os fundamentos do minimalismo judicial de Sunstein e, de outro, a crítica à centralidade da jurisdição no processo, aliada à defesa da hermenêutica isomênica, ambas da teoria neoinstitucionalista do processo, enfatiza que o minimalismo - ao menos no modelo sunsteiniano - carece de legitimidade democrática. Como resultado, o artigo demonstra que o modelo minimalista de

\footnotetext{
${ }^{1}$ Artigo recebido em 29/04/2021 e aprovado em 14/10/2021.
} 
Sunstein rejeita os propósitos dialógicos e testificantes da teoria neoinstitucionalista, ao enfatizar a centralidade da jurisdição no processo, contrapondo-se, ainda, à ideia de processo como meio institucionalizante do sistema jurídico. A pesquisa se dá no modelo hermenêutico e tem como raciocínios predominantes o dialético e o hipotético-dedutivo. É de perspectiva interdisciplinar, pois combina Filosofia, Teoria do Direito, Hermenêutica e Direito Processual, tendo sido desenvolvida mediante pesquisa bibliográfica nacional e estrangeira, tendo como fontes secundárias as principais obras de Cass Sunstein e de Rosemiro Pereira Leal atinentes ao tema.

PALAVRAS-CHAVE: Minimalismo judicial; Cass Sunstein; teoria neoinstitucionalista do processo; Rosemiro Pereira Leal; processualidade democrática.

ABSTRACT: This paper asks, as a research problem, the democratic compatibility of Cass Sunstein's judicial minimalism in the light of the neoinstitutionalist procedural theory, developed by Rosemiro Pereira Leal based on a Popperian solid matrix, and adopted as the main theoretical framework for the objections to Sunstein's conception in this writing. Thus, the general article's objective is to oppose the main basis of judicial minimalism with the democratic procedural advocated by the neoinstitutionalist procedural theory. As a hypothesis, it is affirmed that the existing antagonism between, on the one hand, the foundations of Sunstein's judicial minimalism and, on the other, the criticism of the jurisdiction's centrality in the process, allied to the defense of isomenical hermeneutics, both of the neoinstitutionalist procedural theory, emphasizes that the minimalism - at least in the Sunsteinian model - lacks democratic legitimacy. As result, the paper demonstrates that Sunstein's judicial minimalism rejects the dialogical and testifying purposes of neoinstitutionalist theory, emphasizing the jurisdiction's centrality in the process, also opposing the idea of process as an institutionalizing means of the legal system. The research takes place in the hermeneutic model, and its predominant reasoning is dialectical and hypothetical-deductive. It has an interdisciplinary perspective, as it combines Philosophy, Theory of Law, Hermeneutics, and Procedural Law, having been developed through national and foreign bibliographic research, having as secondary sources the principal works of Cass Sunstein and Rosemiro Pereira Leal related to the theme. 
KEYWORDS: Judicial minimalism; Cass Sunstein; neoinstitutionalist procedural theory; Rosemiro Pereira Leal; democratic procedural law.

\section{INTRODUÇÃO}

Por meio da observação das decisões da Suprema Corte dos Estados Unidos, em especial, a partir da década de 1990, Cass Sunstein ${ }^{2}$ identificou e caracterizou o denominado minimalismo judicial. Trata-se, pois, de abordagem utilizada no âmbito do processo decisório, principalmente na jurisdição constitucional, caracterizada pela adoção de teorias em menor escala de abstração, deixando em descoberto alguns pontos das questões em exame, principalmente aquelas que reúnem intensas controvérsias no âmbito moral.

Embora o próprio Sunstein afirme não se tratar de uma teoria completa da interpretação, o minimalismo judicial tem uma base teórica clara, que pode ser compreendida por meio da análise da vasta produção bibliográfica do autor, amplamente citada ${ }^{3}$, inclusive aquelas cujas temáticas não se ligam diretamente ao minimalismo.

A elaboração de Sunstein parte, como dito, da observação das decisões da Suprema Corte dos Estados Unidos, embora advirta que a postura minimalista não seria exclusividade daquele país - assim como o perfil (ou persona) dos juízes heróis, soldados e mudos. ${ }^{4}$ Mas a abordagem enclausurada em quatro modelos, com ênfase no minimalismo, faz pesar sobre as concepções de Sunstein indícios de suas limitações democráticas, divorciadas, pois, do caráter pluralista e complexo das sociedades contemporâneas.

Ademais, a aplicação de uma abordagem ou teoria jurídica não deve se limitar à identificação de perfis ou à tentativa de repetir modelos reproduzíveis; deve ser submetida a profunda análise a partir de aguda crítica, tendo como pano de fundo o Estado Democrático de Direito. A teoria neoinstitucionalista do processo, de autoria de Rosemiro Pereira Leal, por

\footnotetext{
${ }^{2}$ Cass Sunstein foi professor da Faculdade de Direito de Chicago por 27 anos. Atualmente é professor da Harvard Law School. Tem pesquisas na área da Teoria do Direito, Direito Constitucional e Economia Comportamental. Cf. HARVARD LAW SCHOOL. Faculty Profiles. Cass R. Sunstein. Cambridge: Harvard Law School, 2021.

${ }^{3}$ Dados indicam que Sunstein foi o jurista mais citado nos Estados Unidos no período de 2009 e 2013. Cf. LEITER, Brian. Top Ten Law Faculty (by area) in Scholarly Impact, 2009-2013. Brian Leiter's Law School Rankings, [s. l.], 2014.

${ }^{4}$ As personae constitucionais estão presentes na obra Constitutional personae. Cf. SUNSTEIN, Cass R. Constitutional personae. New York: Oxford University Press, 2015.
} 
ampliar ao extremo as testificações e por representar ruptura com decisionismos, atende a esses requisitos.

Assim, o presente artigo questiona, como problema de pesquisa, a compatibilidade democrática do minimalismo judicial de Sunstein $^{5}$ à luz da teoria neoinstitucionalista do processo, elaborada por Rosemiro Pereira Leal ${ }^{6}$ a partir de forte matriz popperiana, e adotada como marco teórico principal para as objeções à concepção de Sunstein neste escrito. Desse modo, como hipótese, afirma-se que o antagonismo existente entre, de um lado, os fundamentos do minimalismo judicial de Sunstein e, de outro, a crítica à centralidade da jurisdição no processo, aliada à defesa da hermenêutica isomênica, ambas da teoria neoinstitucionalista do processo, enfatiza que o minimalismo - ao menos no modelo sunsteiniano - carece de legitimidade democrática.

O objetivo geral do artigo é contrapor as principais bases do minimalismo judicial de Sunstein à processualidade democrática preconizada pela teoria neoinstitucionalista do processo.

São objetivos específicos do artigo: (a) caracterizar a abordagem minimalista de Sunstein, principalmente por meio dos acordos não totalmente teorizados e da defesa do conservadorismo político de Edmund Burke; (b) testificar, a partir dos preceitos da teoria neoinstitucionalista do processo de Rosemiro Pereira Leal, o modelo minimalista de Sunstein.

O desenvolvimento do trabalho científico se estrutura em dois tópicos, seguidos da conclusão. O tópico dois analisa o minimalismo judicial de Sunstein, apresentando sua estruturação teórica essencial, a saber, os acordos não totalmente teorizados e o conservadorismo político de Edmund Burke. $^{7} \mathrm{O}$ tópico três, fundado da teoria neoinstitucionalista do processo de Rosemiro Pereira Leal ${ }^{8}$, oferece objeções ao pensamento

\footnotetext{
${ }^{5}$ SUNSTEIN, Cass R. One case at a time: judicial minimalism on the Supreme Court. Massachusetts: Harvard University Press, 1999; SUNSTEIN, Cass R. Beyond judicial minimalism. Public Law \& Legal Theory Working Paper, Chicago, n. 237, set. 2008; SUNSTEIN, Cass R. Constitutional personae. New York: Oxford University Press, 2015.

${ }^{6}$ LEAL, Rosemiro Pereira. A teoria neoinstitucionalista do processo: uma trajetória conjectural. Belo Horizonte: Arraes Editores, 2013; LEAL, Rosemiro Pereira. Teoria geral do processo: primeiros estudos. 13. ed. Belo Horizonte: Fórum, 2016; LEAL, Rosemiro Pereira. Teoria processual da decisão jurídica. Belo Horizonte: D’Plácido, 2016.

${ }^{7}$ BURKE, Edmund. Reflexões sobre a Revolução na França. Tradução, apresentação e notas de José Miguel Nanni Soares. São Paulo: Edipro, 2014.

${ }^{8}$ LEAL, Rosemiro Pereira. A teoria neoinstitucionalista do processo: uma trajetória conjectural. Belo Horizonte: Arraes Editores, 2013; LEAL, Rosemiro Pereira. Teoria geral do processo: primeiros estudos. 13. ed. Belo
} 
de Sunstein, focando, especialmente, na crítica à centralidade da jurisdição, no autoritarismo velado, na forma de limitação das teorias abstratas e no culto à tradição (expresso pela remissão ao conservadorismo político de Edmund Burke ${ }^{9}$ ).

A pesquisa se dá no modelo hermenêutico ${ }^{10}$ e tem como raciocínios predominantes o dialético e o hipotético-dedutivo. É de perspectiva interdisciplinar, pois combina Filosofia, Teoria do Direito, Hermenêutica e Direito Processual, tendo sido desenvolvida mediante pesquisa bibliográfica nacional e estrangeira, tendo como fontes secundárias as principais obras de Cass Sunstein e de Rosemiro Pereira Leal atinentes ao tema.

\section{O MINIMALISMO JUDICIAL DE CASS SUNSTEIN}

Alicerçado nos conceitos dos acordos não totalmente teorizados, do conservadorismo político de Edmund Burke, Sunstein caracteriza o minimalismo judicial como abordagem utilizada no âmbito do processo decisório, em que os juízes limitam as decisões ao núcleo mínimo essencial para solução das controvérsias, evitando, ainda, a utilização de regras ou teorias com alta carga de abstração. Esse núcleo minimalista ocorre em duas dimensões: a da estreiteza (narrowness) e a da superficialidade (shallowness).

A estreiteza ${ }^{11}$ opõe-se ao propósito de extensão e evidencia a necessidade de os juízes se restringirem ao caso em exame, quer faticamente, quer juridicamente. Essa dimensão pode ser captada na afirmação do Chief Justice Roberts: “[...] se não é necessário decidir mais, é necessário não mais decidir [...]". 1213

Já a dimensão da superficialidade traduz, na abordagem minimalista, a ideia de que os argumentos tendem a ser menos profundos ou abstratos. Tome-se, como exemplo, o processo

Horizonte: Fórum, 2016; LEAL, Rosemiro Pereira. Teoria processual da decisão jurídica. Belo Horizonte: D’Plácido, 2016.

${ }^{9}$ BURKE, Edmund. Reflexões sobre a Revolução na França. Tradução, apresentação e notas de José Miguel Nanni Soares. São Paulo: Edipro, 2014.

${ }^{10}$ GUSTIN, Miracy Barbosa de Sousa; DIAS, Maria Tereza Fonseca. (Re)pensando a pesquisa jurídica: teoria e prática. 4. ed. rev. e atual. Belo Horizonte: Del Rey, 2015. p. 12.

${ }^{11}$ A estreiteza, no minimalismo judicial de Sunstein, é uma dimensão sempre relativa, nunca absoluta, já que as decisões minimalistas poderão ser mais ou menos restritas, se comparadas com outras também ditas minimalistas. Cf. SUNSTEIN, Cass R. One case at a time: judicial minimalism on the Supreme Court. Massachusetts: Harvard University Press, 1999. p. 10.

12 ESTADOS UNIDOS DA AMÉRICA. Court of Appeals. District of Columbia Circuit. Petition for judicial review $n^{o}$ 03-1008. PDK Laboratories Inc., Petitioner, v. United States Drug Enforcement Administration, Respondent. Chief Justice Roberts, 26 mar. 2004, tradução nossa.

${ }^{13}$ Texto original: "[...] if it is not necessary to decide more, it is necessary not to decide more [...].". 
decisório na jurisdição constitucional. Nele há considerável tendência de que os argumentos sejam abstratizados em níveis mais acentuados. Ou seja, as controvérsias de matiz constitucional demandam, para sua solução, fundamentações em torno do significado e amplitude do texto constitucional, remontando, por vezes, à atualização dos compromissos constitucionais firmados à época da elaboração do seu texto, revolvendo conceitos de alta carga filosófica, política, sociológica, histórica, entre outros. A superficialidade minimalista, portanto, evita maiores compromissos em torno de uma teoria determinante, principalmente em questões envolvendo direitos fundamentais.

A adoção do minimalismo como técnica hermenêutica apresenta-se, segundo argumenta Sunstein ${ }^{14}$, como alternativa, por exemplo, para a relação entre moral e direito, e tem como importante âmbito de incidência o plano constitucional. Seu espaço de aplicação, entretanto, é amplo, na medida em que propõe um limite na teorização e na abstração dos pronunciamentos judiciais em geral.

O minimalismo judicial prefere passos pequenos e cautelosos, gradualmente sedimentados em decisões e práticas do passado, enfatizando, sobretudo, “[...] os limites das teorias de grande escala"15 16 . Em verdade, o minimalismo não quer adotar qualquer tipo de teoria fundamental. Prefere superficialidade à profundidade.

Essas características, segundo Sunstein ${ }^{17}$, estariam ligadas a razões essencialmente pragmáticas, já que o minimalismo atenta para os custos da decisão e para os custos dos seus erros, acreditando que tal abordagem poderá minimizar tanto um quanto o outro.

Há diferentes graus de minimalismo. Alguns minimalistas o elegem para quase todos os contextos, embora advirta Sunstein ${ }^{18}$ que o minimalismo não é uma abordagem para todas as circunstâncias. Outros, de forma mais consciente e cuidadosa, entendem que a adoção da abordagem minimalista é casuística. Nessa linha, Sunstein ${ }^{19}$ ressalva que, em certos contextos, argumentos como os de que a abordagem minimalista reduz os custos das decisões ou de seus erros não proporcionam uma defesa adequada ao minimalismo judicial. Isso

\footnotetext{
${ }^{14}$ SUNSTEIN, Cass R. Constitutional personae. New York: Oxford University Press, 2015.

${ }^{15}$ SUNSTEIN, Cass R. Constitutional personae. New York: Oxford University Press, 2015. p. 16, tradução nossa.

${ }^{16}$ Texto original: "[...] the limits of large-scale theories."

${ }^{17}$ SUNSTEIN, Cass R. Beyond judicial minimalism. Public Law \& Legal Theory Working Paper, Chicago, n. 237, set. 2008

${ }^{18}$ SUNSTEIN, Cass R. Constitutional personae. New York: Oxford University Press, 2015.

${ }^{19}$ SUNSTEIN, Cass R. Beyond judicial minimalism. Public Law \& Legal Theory Working Paper, Chicago, $\mathrm{n}$. 237, set. 2008.
} 
porque, nesses casos, ao dar pequenos passos, os tribunais que adotam uma postura minimalista impõem graves encargos, especialmente para instâncias inferiores.

Sunstein $^{20}{ }^{21}$, ainda, argumenta que "Os minimalistas acreditam que deixando as questões centrais não decididas, podem manter um amplo espaço para o autogoverno, demonstrando, ao mesmo tempo, respeito às pessoas que discordam sobre questões fundamentais.". Ao deixar em descoberto as questões que não mais precisam ser decididas, os minimalistas, por meio de abordagens menos abstratas, pretendem atuar como catalisadores do processo político e dos respectivos resultados.

Antes de direcionar as críticas que se pretende apresentar nesse artigo, convém explicitar aquelas que podem ser consideradas como principais premissas do minimalismo judicial de Sunstein: os acordos não totalmente teorizados, marca que sintetiza o pensamento do autor ${ }^{22}$, e o conservadorismo político, na acepção desenvolvida por Edmund Burke. ${ }^{23}$ Serão sobre essas bases minimalistas que as objeções da processualidade democrática da teoria neoinstitucionalista incidirão.

\subsection{Os acordos não totalmente teorizados}

Segundo o próprio Sunstein ${ }^{24}$, o que melhor define todo seu pensamento são os incompletely theorized agreements, em tradução livre, os acordos não totalmente teorizados. ${ }^{25}$

\footnotetext{
${ }^{20}$ SUNSTEIN, Cass R. Beyond judicial minimalism. Public Law \& Legal Theory Working Paper, Chicago, n. 237 , p. 1, set. 2008, tradução nossa.

${ }^{21}$ Texto original: "Minimalists believe that by leaving central issues undecided, they can maintain ample space for self-governance while also demonstrating respect to people who disagree on fundamental matters."

${ }^{22}$ SUNSTEIN, Cass R. A conversation with Cass Sunstein. [Entrevista cedida a] Tyler Cowen. Conversations with Tyler. Washington: Mercatus Center, 2016.

${ }^{23}$ BURKE, Edmund. Reflexões sobre a Revolução na França. Tradução, apresentação e notas de José Miguel Nanni Soares. São Paulo: Edipro, 2014.

${ }^{24}$ SUNSTEIN, Cass R. A conversation with Cass Sunstein. [Entrevista cedida a] Tyler Cowen. Conversations with Tyler. Washington: Mercatus Center, 2016.

25 Preferiu-se adotar neste artigo a tradução acordos não totalmente teorizados para o termo incompletely theorized agreements, com o objetivo de enfatizar que a aplicação dessa elaboração se dá, muitas vezes, de modo consciente, não sendo sempre fruto de eventual insuficiência de argumentos dos envolvidos. Registre-se, contudo, outras traduções, como a de Diego Werneck Arguelhes e Pedro Jimenes Cantisano (SUNSTEIN, Cass R. Acordos Constitucionais sem Teorias Constitucionais. Tradução de Diego Werneck Arguelhes e Pedro Jimenez Cantisano. Revista de Direito Administrativo, Rio de Janeiro, v. 246, p. 79-94, set. 2007), que preferiram acordos não completamente fundamentados, e a de Antonio Moreira Maués (MAUÉS, Antonio Moreira. Jogando com os precedentes: regras, analogias, princípios. Revista Direito GV, São Paulo, v. 8, n. 2, p. 587-624, dez. 2012), que traduziu a expressão como acordos teóricos incompletos, observada, também, no artigo de Flávio Quinaud Pedron e Lucas Borges Santos (PEDRON, Flávio Quinaud; SANTOS, Lucas Borges.
} 
Por meio deles seria possível descobrir quais direitos cabem a cada grupo ou indivíduo e, ainda, como agir em relação a esses sem o comprometimento de concepções distintas acerca da moralidade, ou sem a necessidade que se saiba o que pensam os envolvidos sobre seu fundamento. Em outras palavras, com os acordos não totalmente teorizados pode-se concordar sobre abstrações sem concordar sobre o significado delas.

Assim, nos casos difíceis, poder-se-ia chegar a um consenso sobre o direito, mesmo quando as teorias que se digladiam sejam completamente divergentes. ${ }^{26}$ Para tanto, nos acordos não totalmente teorizados, ocorre o que Sunstein $^{27}$ denomina de "descida conceitual" 28 , que se opera pelo que o autor denomina de "uso construtivo do silêncio" - o exato ponto em que a teorização se torna incompleta e menos abstrata -, com a pretensa capacidade de produzir convergência em meios marcados pela heterogeneidade; ou seja, a teorização incompleta representaria um caminho para superação do dissenso e viabilizaria a aceitação de resultados, sem que os indivíduos tenham que compreender ou convergir sobre

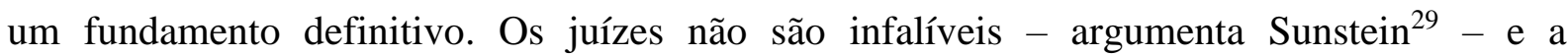
teorização incompleta agiria de modo a reconhecer essa falibilidade.

Sunstein $^{30}$ indica que os acordos não totalmente teorizados têm aplicação em diversos contextos. Em amparo a essa afirmação, o autor cita o exemplo do direito à liberdade religiosa. A concretização desse direito pode comportar uma série de argumentos, que vão desde a defesa da dignidade da pessoa humana, até outros, de matriz utilitarista. Apesar disso, haveria um ponto de ação do silêncio capaz de viabilizar o acordo (não totalmente teorizado), permitindo que os envolvidos assintam sobre a importância da preservação desse direito, sem a necessidade de abstrações amplas em torno do seu fundamento, o que certamente conduziria ao dissenso.

(Des)semelhanças entre a figura do precedente na tradição jurídica do common law e no direito brasileiro. Revista Eletrônica de Direito Processual, Rio de Janeiro, ano 15, v. 22, n. 2, p. 323-347, maio/ago. 2021).

${ }^{26}$ SUNSTEIN, Cass R. Incompletely theorized agreements commentary. Harvard Law Review, Cambridge, n. 108, p. 1733-1772, 1994; SUNSTEIN, Cass R. Legal reasoning and political conflict. New York: Oxford University Press, 1996; SUNSTEIN, Cass R. Incompletely theorized agreements in Constitutional Law. Public Law \& Legal Theory Working Paper, Chicago, n. 147, jan. 2007.

${ }^{27}$ SUNSTEIN, Cass R. Incompletely theorized agreements in Constitutional Law. Public Law \& Legal Theory Working Paper, Chicago, n. 147, p. 3, jan. 2007, tradução nossa.

${ }^{28}$ Texto original: "conceptual descent".

${ }^{29}$ SUNSTEIN, Cass R. Incompletely theorized agreements in Constitutional Law. Public Law \& Legal Theory Working Paper, Chicago, n. 147, p. 3, jan. 2007.

${ }^{30}$ SUNSTEIN, Cass R. Incompletely theorized agreements in Constitutional Law. Public Law \& Legal Theory Working Paper, Chicago, n. 147, p. 3, jan. 2007. 
Sunstein $^{31}$, assim, afirma que “[...] quando as pessoas divergem sobre uma proposição (relativamente) de alto nível, elas podem ser capazes de concordar quando baixam o nível de abstração". ${ }^{32}$ Outro exemplo de aplicação dos acordos não totalmente teorizados estaria na Declaração Universal dos Direitos Humanos, de 1948. Em determinada fase na elaboração do seu texto, Jacques Maritain ${ }^{33}$, filósofo envolvido no projeto, assim afirmou: “Sim, [...] estamos de acordo sobre os direitos, mas na condição de que ninguém nos pergunte o porquê". 34

Assim, o uso dos acordos não totalmente teorizados no processo decisório jurisdicional representa a chave que abre as portas para o minimalismo judicial.

Sunstein $^{35}$ argumenta que as pessoas, quando teorizam em um alto nível de abstração, o fazem para demonstrar um viés, confusão ou inconsistência; um esforço que os operadores do Direito não devem abandonar, já que "não seria sensato celebrar a modéstia teórica em todos os momentos e em todos os contextos". 36

Contudo, é frente aos custos das decisões, sobretudo de seus erros, que os julgamentos fundados nos acordos não totalmente teorizados (incluídos os julgamentos minimalistas) exercem uma importante função.

Eles ajudam fazer as constituições e o Direito Constitucional possível; ajudam até a tornar a vida social possível. O silêncio - em algo que pode se comprovar falso, obtuso ou excessivamente contencioso - pode ajudar a minimizar o conflito, permitindo que o presente aprenda com o futuro e que se economize muito tempo e dinheiro. ${ }^{37} 38$

Outra vantagem residiria no fato de que quando a decisão está fundamentada em um princípio ou regra de menor abstração, aquele que sucumbe não perderia os argumentos de sua tese. Isso porque ela não seria rejeitada ou declarada inadmissível, já que a análise terá

\footnotetext{
${ }^{31}$ SUNSTEIN, Cass R. Legal reasoning and political conflict. New York: Oxford University Press, 1996. p. 37, tradução nossa.

32 Texto original: “[...] When people diverge on some (relatively) high-level proposition, they might be able to agree when they lower the level of abstraction".

33 MARITAIN, Jacques. Introduction. In: UNITED NATIONS EDUCATIONAL, SCIENTIFIC AND CULTURAL ORGANIZATION. Human Rights: comments and interpretation. Paris: UNESCO, 1948. p. I, tradução nossa.

${ }^{34}$ Texto original: "Yes, [...] we agree about the rights but on condition that no one asks us why".

${ }^{35}$ SUNSTEIN, Cass R. Incompletely theorized agreements in Constitutional Law. Public Law \& Legal Theory Working Paper, Chicago, n. 147, p. 13, jan. 2007, tradução nossa.

${ }^{36}$ Texto original: "It would not be sensible to celebrate theoretical modesty at all times and in all contexts."

${ }^{37}$ SUNSTEIN, Cass R. Incompletely theorized agreements in Constitutional Law. Public Law \& Legal Theory Working Paper, Chicago, n. 147, p. 13, jan. 2007, tradução nossa.

${ }^{38}$ Texto original: "They help make constitutions and constitutional law possible; they even help make social life possible. Silence - on something that may prove false, obtuse, or excessively contentious - can help minimize conflict, allow the present to learn from the future, and save a great deal of time and expense."
} 
sido feita por meio de corte menos profundo no plano da abstração de uma teoria. Evitar-se-ia, desse modo, oposições desnecessárias, sobretudo numa deliberação colegiada.

\subsection{O conservadorismo de Edmund Burke}

Sunstein vê no pensamento de Edmund Burke e no seu conservadorismo político um importante referencial teórico. ${ }^{39}$ Edmund Burke ${ }^{40}$ foi um filósofo e político anglo-irlandês, autor da obra Reflexões sobre a Revolução na França. Publicada em 1790, Reflexões é concebida como um manifesto da contrarrevolução ${ }^{41}$ e encarada como a fundadora do conservadorismo político moderno. ${ }^{42}$

Nessa obra, sem desconsiderar que as entranhas do poder na França estavam contaminadas, Burke se opõe à revolução como meio para a transformação daquele país. Para o autor anglo-irlandês, a reforma seria o processo adequado para as transformações necessárias. Seu referencial era a Revolução Gloriosa, de 1668, que culminou no fim da monarquia absolutista da Inglaterra.

A conceituação do minimalismo judicial de Sunstein tem forte influência do pensamento de Burke. Como afirma, "aqueles que enfatizam os acordos não totalmente teorizados têm um débito evidente com Edmund Burke, que foi, em certo sentido, o grande teórico da teorização incompleta" ${ }^{434}$, sendo esta a abordagem característica do minimalismo.

Edmund Burke ${ }^{45}$ entendia a jurisprudência ${ }^{46}$, apesar de seus erros, como a "razão acumulada dos séculos", afirmação que Sunstein reproduz na teorização do minimalismo

\footnotetext{
39 O pensamento burkeano permeia grande parte das obras de Sunstein, inclusive aquelas não dedicadas à temática do minimalismo judicial. Cf. Sunstein, 2010, 2016, 2019, 2019.

${ }^{40}$ BURKE, Edmund. Reflexões sobre a Revolução na França. Tradução, apresentação e notas de José Miguel Nanni Soares. São Paulo: Edipro, 2014.

${ }^{41}$ MACKINTOSH, James. Vindiciae gallicae: defence of the french revolution and its English admires, against the accusations of the right Hon. Edmund Burke. 3. ed. London: GGJ \& J. Robinson, 1792. p. xi.

${ }^{42}$ SOARES, José Miguel Nanni. Introdução. In: BURKE, Edmund. Reflexões sobre a Revolução na França. Tradução, apresentação e notas de José Miguel Nanni Soares. São Paulo: Edipro, 2014. p. 7-21.

${ }^{43}$ SUNSTEIN, Cass R. Incompletely theorized agreements in Constitutional Law. Public Law \& Legal Theory Working Paper, Chicago, n. 147, p. 15, jan. 2007, tradução nossa.

${ }^{44}$ Texto original: "Those who emphasize incompletely theorized agreements owe an evident debt to Edmund Burke, who was, in a sense, the great theorist of incomplete theorization."

${ }^{45}$ BURKE, Edmund. Reflexões sobre a Revolução na França. Tradução, apresentação e notas de José Miguel Nanni Soares. São Paulo: Edipro, 2014. p. 114.

${ }^{46} \mathrm{O}$ sentido do termo "jurisprudência" empregado pelo filósofo irlandês não se refere às decisões judiciais reiteradas sobre mesmo tema, no mesmo sentido e consideradas em conjunto - uma das traduções possíveis do termo, mas não a mais remota; Edmund Burke se referia ao estudo do direito posto, do direito natural, além das
} 
judicial. Sunstein, portanto, importa do pensamento burkeano o culto às tradições e a ideia de respeito cívico como anteparo para as conclusões minimalistas.

Para Sunstein há duas espécies de minimalismo; uma racionalista e outra mais "burkeana", também chamada por ele de "minimalismo burkeano". ${ }^{47}$ Entretanto, em maior ou menor grau, é evidente a inflexão burkeana em ambas as formas do minimalismo e em todo pensamento do autor norte-americano.

\section{CRÍTICA NEOINSTITUCIONALISTA AO MINIMALISMO JUDICIAL}

A partir desse tópico propõe-se uma análise do minimalismo judicial e de sua fundamentação, adotando, como marco teórico, a teoria neoinstitucionalista do processo, elaborada por Rosemiro Pereira Leal, que a partir de forte crítica aos "déficits de legitimidade [...] de diversas escolas do pensamento processual [...], propõe um significativo giro teórico no Direito Processual a partir de suas novas bases constitucionais democráticas". ${ }^{48}$

Tal elaboração teórica tem grande incidência da epistemologia de Karl Popper, sem necessariamente reproduzir o seu pensamento, mas, em verdade, aproveitando-o em reflexões acerca do direito democrático, opondo-se à ciência dogmática do direito.

\subsection{O autoritarismo escamoteado do minimalismo judicial}

O minimalismo judicial de Sunstein, ao propor decisões marcadas pela estreiteza e superficialidade e restritas às particularidades do caso concreto, busca uma limitação no âmbito de incidência das decisões judiciais, na pretensão de racionalizar intervenções, por vezes, indevidas, do Poder Judiciário nas mais diversas esferas de deliberação sociais. Essa proposta encontra fundamento, na teoria de Sunstein, nos já expostos acordos não totalmente teorizados, ideia permeada pela limitação do uso das teorias e abstrações em grande escala.

regras de Direito Internacional - a Teoria do Direito. Cf. GARNER, Bryan A. (ed.). Black's law dictionary. 9. ed. Saint Paul: West, 2009. p. 932.

${ }^{47}$ SUNSTEIN, Cass R. Constitutional personae. New York: Oxford University Press, 2015. p. 68.

${ }^{48}$ LEAL, André Cordeiro. Instrumentalidade do processo em crise. Belo Horizonte: Mandamentos, 2008. p. 138. 
Esse propósito, em linhas preliminares, apresenta-se como importante saída, sobretudo ao protagonismo judicial em suas mais variadas acepções, entre elas, a conhecida postura ativista $^{49}$, além de representar alternativa para influxos entre direito e moral.

Paira, no entanto, crítica aos acordos não totalmente teorizados e, por consequência, ao minimalismo judicial. Essa crítica não está na tentativa de obtenção de acordos possíveis em meios de intensa divergência, proposta que soa louvável diante de rápidas e constantes mudanças que o mundo contemporâneo exige. As críticas, aqui formuladas por meio de indagações, são: a quem caberá limitar a teorização de grupos dissonantes? A quem cabe eleger o exato limite da estreiteza e da superficialidade das abordagens ditas minimalistas? Qual o modo para realização de tal limitação teórica?

Observando-se o minimalismo a partir de bases processuais democráticas presentes na teoria neoinstitucionalista do processo, vê-se que, na tentativa de limitar a intervenção judicial, a abordagem de Sunstein acaba reforçando a centralidade da jurisdição no sistema jurídico $^{50}$ e a autoridade do juiz, figura que, na teoria neoinstitucionalista do processo, é apenas

[...] concretizador do ato provimental de encerramento decisório do discurso estrutural do procedimento processualizado pelo due process democrático em suas incidências substancial (substantive) de garantias implantadas constitucionalmente e procedimental (procedural) do modo adequado de aplicação constitucionalmente assegurado. ${ }^{51}$

Na teoria de Sunstein, a abordagem minimalista não está amplamente à disposição das partes, que têm apenas o pedido e os respectivos fundamentos para limitação da abstração dos argumentos. Trata-se, frise-se, de um minimalismo “judicial”, ou seja, próprio aos juízes. Ainda que seu objetivo seja a limitação na abstração dos argumentos das partes, o minimalismo, para efetiva compatibilidade democrática, precisa estabelecer, como premissa, que as características de estreiteza e superficialidade de sua abordagem devem ser produtos do propósito dialógico delas, retirando do seu centro a jurisdição que, substituída pelo processo em seu nível institucionalizante do sistema jurídico, reformula-o como minimalismo

\footnotetext{
${ }^{49}$ Sobre o ativismo, Sunstein procura estabelecer um limite a tal definição, compreendendo-a como postura e frequência com que o Poder Judiciário invade a esfera dos outros poderes, invalidando seus atos e normas. Cf. SUNSTEIN, Cass R. Constitutional personae. New York: Oxford University Press, 2015. p. 41.

${ }^{50}$ LEAL, Rosemiro Pereira. A teoria neoinstitucionalista do processo: uma trajetória conjectural. Belo Horizonte: Arraes Editores, 2013.

${ }^{51}$ LEAL, Rosemiro Pereira. Processo e hermenêutica constitucional a partir do Estado de Direito Democrático. Revista da Faculdade de Direito da UFMG, Belo Horizonte, n. 38, p. 271, 2000, grifo do autor.
} 
processual democrático. No modelo de Sunstein, trata-se o minimalismo (judicial) de recurso hermenêutico - frise-se - precipuamente à disposição do juiz.

A propósito da hermenêutica, importante destacar o quão divergente é o minimalismo do sentido preconizado pela teoria neoinstitucionalista do processo: o da hermenêutica isomênica.

Para Rosemiro Pereira Leal ${ }^{52}$, a compreensão de isonomia ultrapassa a simples "[...] paridade de tempo (prazo) de fala entre partes", devendo ser compreendida por meio do acesso linguístico das postulações e decisões aos sujeitos do procedimento (isotopia), pelo igual direito de interpretação (isomenia) e, por fim, pela garantia em se pleitear a extinção ou modificação das normas (isocrítica).

Essa tríplice decomposição vem de encontro à teorização subjacente ao minimalismo judicial. Primeiro, porque este, com sua defesa dos acordos não totalmente teorizados, limita a abstração dos argumentos das partes, violando a isotopia. Segundo, porque não confere ou distribui de modo equilibrado o direito de interpretação, isto é, não viabiliza um "direito igual de interpretar a lei". ${ }^{53}$ Por último, porque a limitação da teorização dos argumentos na abordagem minimalista, expressada na predileção por decisões estreitas e superficiais, reduz o campo da crítica capaz de levar à extinção ou modificação das normas pelo seu legítimo produtor: o povo. Rosemiro Pereira Leal ${ }^{54}$, nessa linha, afirma que "[...] é o POVO que faz e garante as suas próprias conquistas conceituais pelo processo constitucional legiferante do que é devido (garantido, assegurado), não o juiz que é funcionário do POVO”.

Além disso, o minimalismo de Sunstein não deixa claro qual critério a ser utilizado pelo juiz na definição do limite da amplitude ou profundidade da abordagem minimalista, nem o modo como tal limitação teórica é exercida. Não se trata, portanto, de um critério instituído a partir da lei, mas sim apesar da lei e à margem dela, violando "os princípios concorrentes de atuação do agir" ${ }^{25}$, ínsitos do direito democrático.

\footnotetext{
${ }^{52}$ LEAL, Rosemiro Pereira. A teoria neoinstitucionalista do processo: uma trajetória conjectural. Belo Horizonte: Arraes Editores, 2013. p. 11.

${ }^{53}$ LEAL, Rosemiro Pereira. A teoria neoinstitucionalista do processo: uma trajetória conjectural. Belo Horizonte: Arraes Editores, 2013. p. 5.

${ }^{54}$ LEAL, Rosemiro Pereira. Processo e hermenêutica constitucional a partir do Estado de Direito Democrático. Revista da Faculdade de Direito da UFMG, Belo Horizonte, n. 38, p. 271, 2000.

${ }^{55}$ LEAL, Rosemiro Pereira. Processo e hermenêutica constitucional a partir do Estado de Direito Democrático. Revista da Faculdade de Direito da UFMG, Belo Horizonte, n. 38, p. 271, 2000.
} 
A marca popperiana da teoria neoinstitucionalista do processo concebe que "[...] a linguagem teórico-processual apresenta uma relação de inclusão com as ideias humanas de vida, liberdade e dignidade, daí não se conceber vida humana sem concomitante abertura ao contraditório, ampla defesa e isonomia". ${ }^{56}$ Logo, quer por deixar em aberto o momento e o modo para sua adoção, quer por não definir a extensão da postura minimalista, a teoria de Sunstein reforça a figura de um decisor talentoso, capaz de apontar soluções às mais diversas controvérsias que lhe são postas.

O minimalismo, também à luz da base teórica neoinstitucionalista, alijaria o processo como instrumento capaz de produzir discussões críticas, frutos de propósitos testificantes e de uma realidade efetivamente democrática, recusando a processualização do espaço linguístico, resumindo-se a mera técnica a serviço do autoesquecimento. ${ }^{57}$ Isso porque,

o processo é na pós-modernidade um discurso argumentativo de compartilhada fixação procedimental ad hoc no sentido normativo em níveis instituinte, constituinte e constituído do direito. [...] Esse direito discursivo, isto é, essa linguisticidade produtiva e institutiva de normas, como processo jurídico, é que seria instituinte (constituinte-originário) e constituinteconstitucional de um direito a ser ativado (pós-ativo = positivo) e não mais um direito ativo miticamente surgido da natureza ou de um poder instituinte (constituinte) originário (egresso) do leito das culturas ou da razão pura ou apriorística. $^{58}$

A compreensão da função argumentativa (e de sua limitação), encerrada no minimalismo judicial de Sunstein, conferiria, a partir da perspectiva neoinstitucionalista, efeitos normativos a "[...] enunciados só reveláveis aos juristas e provindos de um sujeito suposto personificado na ordem jurídica de um sistema social e político". 59

Assim, a pretexto de fomentar o retorno do debate de questões controvertidas para a sociedade, o minimalismo exclui o processo democrático - eixo central da teoria neoinstitucionalista - do plano instituinte e constituinte do direito.

\section{2. $\mathrm{O}$ culto à tradição no minimalismo}

\footnotetext{
56 LEAL, Rosemiro Pereira. A teoria neoinstitucionalista do processo: uma trajetória conjectural. Belo Horizonte: Arraes Editores, 2013. p. 81, grifo do autor.

57 LEAL, Rosemiro Pereira. A teoria neoinstitucionalista do processo: uma trajetória conjectural. Belo Horizonte: Arraes Editores, 2013. p. 85.

${ }^{58}$ LEAL, Rosemiro Pereira. Teoria geral do processo: primeiros estudos. 13. ed. Belo Horizonte: Fórum, 2016. p. 169, grifos do autor.

${ }^{59}$ LEAL, Rosemiro Pereira. Teoria processual da decisão jurídica. Belo Horizonte: D’Plácido, 2016. p. 172.
} 
Ao sustentar a aplicação dos acordos não totalmente teorizados, Sunstein ${ }^{60}$ procura justificá-los, entre outros argumentos, pelo propósito da estabilidade social, intento compartilhado pelo minimalismo judicial, que tem no primeiro sua base teórica.

Esse sentido é combatido pela teoria neoinstitucionalista do processo naquilo que Rosemiro Pereira Leal ${ }^{61}$ denuncia ser "o fetiche da missão social da decisão". Afirma o autor:

As decisões silogísticas que orientam a proibição do non-liquet nas legislações modernas emanaram da combinação artificiosa do método exegético dos franceses (idolatria das lei), pandectista dos alemães (culto do corpus juris) e analítico dos ingleses (empirismo da indução-dedução) dos séculos XVIII e XIX, implantadores da dogmática hermeneutizada em que a decisão dos juízes (judges made law) do common law dos ingleses, como síntese silogística das premissas legais do exegetismo do civil law dos franceses e dos alemães, poderia, com base no princípio da compulsoriedade decisória necessária à unidade dos sistemas jurídicos, resolver os conflitos por valores jurisprudenciais paralelos ao mundo rígido das leis. ${ }^{62}$

Tais críticas, quando direcionadas ao minimalismo judicial de Sunstein, só reforçam o modo com que tal teoria, ainda que reformulando conceitos e sob novas roupagens, repete equívocos de escolas superadas.

Sunstein, como já destacado, indica o conservadorismo político de Edmund Burke como importante referencial teórico do seu minimalismo judicial, preferindo passos pequenos e cautelosos, sedimentados em práticas do passado, chegando a citar trecho da obra Reflexões sobre a Revolução na França, em que o próprio Burke ${ }^{63}$ afirma:

E a primeira de todas as ciências, a ciência da jurisprudência ${ }^{64}$, orgulho do intelecto humano que, com todos os seus defeitos, redundâncias e erros, é a razão acumulada dos séculos, combinando os princípios da justiça original com a infinita variedade das preocupações humanas, seria abandonada como uma pilha de erros descartados. A autossuficiência pessoal e a arrogância (companheiras certas de todos os que jamais conheceram uma sabedoria superior à sua) usurpariam os tribunais..$^{65}$

\footnotetext{
${ }^{60}$ SUNSTEIN, Cass R. Incompletely theorized agreements in Constitutional Law. Public Law \& Legal Theory Working Paper, Chicago, n. 147, jan. 2007.

${ }^{61}$ LEAL, Rosemiro Pereira. Teoria processual da decisão jurídica. Belo Horizonte: D’Plácido, 2016. p. 53.

${ }^{62}$ LEAL, Rosemiro Pereira. Teoria processual da decisão jurídica. Belo Horizonte: D’Plácido, 2016. p. 53, grifos do autor.

${ }_{63}$ BURKE, Edmund. Reflexões sobre a Revolução na França. Tradução, apresentação e notas de José Miguel Nanni Soares. São Paulo: Edipro, 2014. p. 114.

${ }^{64} \mathrm{Cf}$. nota explicativa do termo "jurisprudência" na seção 2.2 acima.

${ }^{65} \mathrm{Em}$ Constitutional Personae, cita o trecho original da obra de Edmund Burke: "And first of all, the science of jurisprudence, the pride of the human intellect, which, with all its defects, redundancies, and errors, is the collected reason of ages, combining the principles of original justice with the infinite variety of human concerns, as a heap of old exploded errors, would no longer be studied. Personal self-sufficiency and arrogance (the certain attendants upon all those who have never experienced a wisdom greater than their own) would usurp the
} 
Ainda que sem aparentemente idolatrar a lei ${ }^{66}$, o minimalismo, com seu culto a uma suposta racionalidade acumulada ao longo do tempo, fundada em tradições e práticas do passado, como preconizado por Edmund Burke, renova, na esteira das críticas elaboradas por Rosemiro Pereira Leal, a defesa de práticas antigas e superadas, a exemplo da Escola Pandectista, recriando, tal como os alemães, um sistema dogmático por meio de reconstrução de instituições e institutos vetustos.

Entretanto, só o propósito conservador não é suficiente para a estruturação teórica do minimalismo judicial e para descrever sua abordagem hermenêutica. $\mathrm{O}$ atuar caracterizado pela estreiteza e superficialidade, aliado à limitação das abstrações em larga escala, só é possível - destaque-se novamente - por juízes talentosos que, nas palavras de Rosemiro Pereira Leal ${ }^{67}$, são “[...] juízes sábios e omnicompreensivos [...] moralizadores da lei quando esta fosse insuficiente para traduzir o espírito popular (volksgeist)".

Burke via na tradição do povo inglês o fator determinante para o sucesso da Revolução Gloriosa, referencial para as críticas que elaborou à Revolução Francesa. Desse modo, afirmou: "Sabemos e, o que é mais importante, sentimos intimamente que a religião é a base da sociedade e a fonte de todo bem e de todo consolo.". ${ }^{6}$

Havendo, pois, um sentimento de íntima ligação entre sociedade e religião, natural que o Estado não fugisse desse modelo. Assim, Burke ${ }^{69}$ assevera: “A consagração do Estado por uma religião estatal é necessária também para produzir um saudável terror sobre os cidadãos livres".

E se os compromissos fundamentais dos ingleses, no modelo da Revolução Gloriosa, estavam fundados na religião, é de se concluir que toda autoridade dos cargos públicos tinha um componente sagrado. É o que se observa da afirmação do político anglo-irlandês:

Quando o povo se vir livre de toda ambição da vontade egoísta, o que é absolutamente impossível de se obter sem a religião; quando tiver

tribunal.”. Cf. SUNSTEIN, Cass R. Constitutional personae. New York: Oxford University Press, 2015. p. 16. Preferiu-se, no presente artigo, a citação do trecho já traduzido e publicado em língua portuguesa, no Brasil.

${ }^{66}$ Em Constitutional Personae, a partir de observação da Suprema Corte norte-americana, elabora quatro personas constitucionais, a saber, os heróis, os soldados, os minimalistas e os mudos. Entre esses perfis, o autor aponta os soldados como aqueles que demonstram excessiva deferência à lei. Cf. SUNSTEIN, Cass R. Constitutional personae. New York: Oxford University Press, 2015.

${ }^{67}$ LEAL, Rosemiro Pereira. Teoria processual da decisão jurídica. Belo Horizonte: D’Plácido, 2016. p. 53.

${ }^{68}$ BURKE, Edmund. Reflexões sobre a Revolução na França. Tradução, apresentação e notas de José Miguel Nanni Soares. São Paulo: Edipro, 2014. p. 109, grifo nosso

${ }^{69}$ BURKE, Edmund. Reflexões sobre a Revolução na França. Tradução, apresentação e notas de José Miguel Nanni Soares. São Paulo: Edipro, 2014. p. 111. 
consciência de que exerce - e talvez em um grau mais elevado na ordem da delegação - um poder que, para ser legítimo, deve estar de acordo com aquela lei eterna imutável, na qual a vontade se confunde com a razão, terá mais cuidado em não colocar esse poder em mãos vis e incapazes. Quando nomear aos cargos públicos, não confundirá o exercício da autoridade com tarefas deploráveis, mas como funções sagradas. Não se inclinará às sugestões de um sórdido egoísmo, ao capricho cego ou a uma vontade arbitrária, mas conferirá esse poder (ante o qual treme em dar ou receber) somente àqueles em que possa discernir essa proporção predominante de sabedoria e virtude ativas combinadas e adequadas ao cargo, tal como pode ser encontrada na grande e inevitavelmente variada massa de imperfeições e enfermidades humanas. ${ }^{70}$

Assim, ao revisitar o pensamento burkeano, é possível verificar que o respeito cívico deflui da religião, encarada como a base da sociedade para Burke. Essa matriz religiosa contamina os cargos públicos, na visão de Burke, entendidos como funções sagradas.

Merece destaque, também, a incompreensão de Burke e, por conseguinte, de Sunstein, acerca do contraste entre tradições e conflitos. Nesse sentido, MacIntyre ${ }^{71}$ esclarece que esses são conceitos que não se excluem, ou seja, que a continuidade de conflitos é algo próprio da vida da tradição. Nesse sentido, tradição e conservadorismo não se confundem.

A aplicação acrítica do pensamento de Burke, tal como a realizada por Sunstein, só faz enaltecer o dogma da autoridade divina que, no minimalismo, materializa-se na figura do juiz. Não é em vão que ao termo minimalismo se atrela o adjetivo judicial. Ou seja, o minimalismo de Sunstein é uma concepção restrita à figura do juiz, reduzindo as partes à condição de meros espectadores da limitação, muitas vezes moral, da abstração e profundidade dos argumentos, retirando sua legitimidade. O ceticismo acerca das teorias da intepretação, tão defendido como uma virtude minimalista, escamoteia a crença em uma autoridade cuja raiz está no divino; traduz, ainda, um dogma, que só se sustenta, por óbvio, no culto às tradições.

É nessa linha que se afirma que a pecha empirista, democrática e consensual do minimalismo judicial, a partir das objeções levantadas por meio de fundamentos da teoria neoinstitucionalista do processo, renovariam vícios e equívocos de elaborações teóricas superadas.

\section{CONCLUSÃO}

\footnotetext{
${ }^{70}$ BURKE, Edmund. Reflexões sobre a Revolução na França. Tradução, apresentação e notas de José Miguel Nanni Soares. São Paulo: Edipro, 2014. p. 113, grifo nosso.

${ }^{71}$ MACINTYRE, Alasdair. Depois da virtude: um estudo em teoria moral. Tradução de Jussara Simões. Revisão técnica de Helder Buenos Aires de Carvalho. Bauru: EDUSC, 2001. p. 373.
} 
A teoria neoinstitucionalista do processo de Rosemiro Pereira Leal é capaz de fornecer importantes e fundadas objeções ao minimalismo judicial de Sunstein, mesmo se compreendido como abordagem limitada circunstancialmente e, por isso, não aplicável em todas as ocasiões e controvérsias, como afirmado pelo próprio autor norte-americano. Sua elaboração, tal como exposto no tópico dois do artigo, indica quão divergentes são as teorias apresentadas, sugerindo, como exposto no tópico três, pontos obscuros ou deficientes das premissas minimalistas.

As críticas obtidas a partir da análise neoinstitucionalista indicam que o minimalismo judicial reproduz a tentativa de perpetuar modelo processual que tem, no seu centro, a jurisdição. Por essa razão, não é o minimalismo um recurso ou abordagem hermenêutico à disposição das partes, dissociando-se, pois, de propósitos dialógicos e testificantes da teoria neoinstitucionalista do processo.

A limitação na abstração dos argumentos antagônicos - tal como sugerido por Sunstein por meio dos acordos não totalmente teorizados - não se alinha à ideia de processo como meio institucionalizante do sistema jurídico, na medida em que exclui o povo. Trata-se, pois, de recurso hermenêutico limitado, já que não confere acesso linguístico aos sujeitos do procedimento (a isotopia), não permite o direito de completa interpretação (isomenia) e, muito menos, viabiliza criar ou extinguir as normas (isocrítica), tríade que compõe a hermenêutica isomênica defendida pela teoria neoinstitucionalista do processo.

Diferentemente de apontar saídas entre direito e moral ou, ainda, minimizar os custos das decisões e, principalmente, dos seus erros, o minimalismo judicial de Sunstein, analisado e criticado pelo ponto de vista da processualidade democrática neoinstitucionalista, não conduz a inovações ou reformulações amplas e capazes de caracterizar modelo processual efetivamente democrático.

O minimalismo judicial de Sunstein exclui o processo democrático do plano instituinte e constituinte do direito, reforçando o decidir de modo clarividente, onisciente e talentoso de um juiz isolado de críticas e elevado à condição de único produtor da norma, com o agravante de poder limitar o plano de abstração dos argumentos das partes a pretexto de atingir uma suposta pacificação social e obter o consenso em meios de intensa divergência. Visto por esses ângulos, o minimalismo torna a repetir equívocos de escolas jurídicas superadas, a 
exemplo da Escola Pandectista, reforçando um direito que ora se alinha a uma ciência puramente dogmática, ora recria, a seu modo, uma jurisprudência de interesses.

Assim, confirma-se a hipótese de pesquisa, a saber, a de que o antagonismo existente entre, de um lado, os fundamentos do minimalismo judicial de Sunstein e, de outro, a crítica à centralidade da jurisdição no processo, aliada à defesa da hermenêutica isomênica, ambas da teoria neoinstitucionalista do processo, enfatiza que o minimalismo judicial de Sunstein carece de legitimidade democrática.

O minimalismo, para ser entendido como recurso hermenêutico democraticamente viável, necessita ser reformulado, seja quanto ao seu paradigma (que deve ser, efetivamente, o do Estado de Direito Democrático), seja na sua estruturação teórica, retirando a jurisdição de seu centro, o que promoveria sua reformulação até no plano linguístico, passando de um minimalismo judicial para um minimalismo processual democrático, plena e efetivamente à disposição das partes. Do contrário, na contramão do que defende Sunstein, o minimalismo incrementaria os custos das decisões e, principalmente, a magnitude dos seus erros.

\section{REFERÊNCIAS:}

BURKE, Edmund. Reflexões sobre a Revolução na França. Tradução, apresentação e notas de José Miguel Nanni Soares. São Paulo: Edipro, 2014.

ESTADOS UNIDOS DA AMÉRICA. Court of Appeals. District of Columbia Circuit. Petition for judicial review $n^{\circ}$ 03-1008. PDK Laboratories Inc., Petitioner, v. United States Drug Enforcement Administration, Respondent. Chief Justice Roberts, 26 mar. 2004. Disponível em: http://caselaw.findlaw.com/us-dc-circuit/1207124.html. Acesso em: 20 abr. 2021.

GARNER, Bryan A. (ed.). Black's law dictionary. 9. ed. Saint Paul: West, 2009.

GUSTIN, Miracy Barbosa de Sousa; DIAS, Maria Tereza Fonseca. (Re)pensando a pesquisa jurídica: teoria e prática. 4. ed. rev. e atual. Belo Horizonte: Del Rey, 2015.

HARVARD LAW SCHOOL. Faculty Profiles. Cass R. Sunstein. Cambridge: Harvard Law School, 2021. Disponível em: http://hls.harvard.edu/faculty/directory/10871/Sunstein/. Acesso em: 20 abr. 2021. 
LEAL, André Cordeiro. Apresentação. In: LEAL, Rosemiro Pereira. A teoria neoinstitucionalista do processo: uma trajetória conjectural. Belo Horizonte: Arraes Editores, 2013. p. XII-XIV.

LEAL, André Cordeiro. Instrumentalidade do processo em crise. Belo Horizonte: Mandamentos, 2008.

LEAL, Rosemiro Pereira. A teoria neoinstitucionalista do processo: uma trajetória conjectural. Belo Horizonte: Arraes Editores, 2013.

LEAL, Rosemiro Pereira. Processo e hermenêutica constitucional a partir do Estado de Direito Democrático. Revista da Faculdade de Direito da UFMG, Belo Horizonte, n. 38, p. 267-281, 2000. Disponível em: https://revista.direito.ufmg.br/index.php/revista/article/download/1172/1105. Acesso em: 20 abr. 2021.

LEAL, Rosemiro Pereira. Teoria geral do processo: primeiros estudos. 13. ed. Belo Horizonte: Fórum, 2016a.

LEAL, Rosemiro Pereira. Teoria processual da decisão jurídica. Belo Horizonte: D’Plácido, $2016 b$.

LEITER, Brian. Top Ten Law Faculty (by area) in Scholarly Impact, 2009-2013. Brian Leiter's Law School Rankings, [s. l. $]$, 2014. Disponível em: http://www.leiterrankings.com/faculty/2014_scholarlyimpact.shtml. Acesso em: 20 abr. 2021.

MACINTYRE, Alasdair. Depois da virtude: um estudo em teoria moral. Tradução de Jussara Simões. Revisão técnica de Helder Buenos Aires de Carvalho. Bauru: EDUSC, 2001.

MACKINTOSH, James. Vindiciae gallicae: defence of the french revolution and its English admires, against the accusations of the right Hon. Edmund Burke. 3. ed. London: GGJ \& J. $\quad 1792 . \quad$ Robinson, Disponível em: https://books.google.com.br/books?id=ltdBAAAAcAAJ\&dq=vindiciae $\% 20$ gallicae $\% 2$ 0james\%20mackintosh\&hl=pt-BR\&pg=PP7\#v=onepage\&q\&f=false. Acesso em: 20 abr. 2021.

MARITAIN, Jacques. Introduction. In: UNITED NATIONS EDUCATIONAL, SCIENTIFIC AND CULTURAL ORGANIZATION. Human Rights: comments and interpretation. Paris: UNESCO, 1948. p. I-IX. Acesso em: 20 abr. 2021. 
MAUÉS, Antonio Moreira. Jogando com os precedentes: regras, analogias, princípios. Revista Direito GV, São Paulo, v. 8, n. 2, p. 587-624, dez. 2012. Disponível em: https://doi.org/10.1590/S1808-24322012000200009. Acesso em: 17 jul. 2021.

PEDRON, Flávio Quinaud; SANTOS, Lucas Borges. (Des)semelhanças entre a figura do precedente na tradição jurídica do common law e no direito brasileiro. Revista Eletrônica de Direito Processual, Rio de Janeiro, ano 15, v. 22, n. 2, p. 323-347, maio/ago. 2021. Disponível em: https://www.epublicacoes.uerj.br/index.php/redp/article/view/48065/37809. Acesso em: 31 ago. 2021.

SOARES, José Miguel Nanni. Introdução. In: BURKE, Edmund. Reflexões sobre a Revolução na França. Tradução, apresentação e notas de José Miguel Nanni Soares. São Paulo: Edipro, 2014. p. 7-21.

SUNSTEIN, Cass R. A conversation with Cass Sunstein. [Entrevista cedida a] Tyler Cowen. Conversations with Tyler. Washington: Mercatus Center, 2016. Disponível em: https://www.mercatus.org/events/conversations-tyler-conversation-cass-sunstein. Acesso em: 20 abr. 2021.

SUNSTEIN, Cass R. A era do radicalismo: entenda por que as pessoas se tornam extremistas. Trad. Lucienne Scalzo. Rio de Janeiro: Elsevier, 2010.

SUNSTEIN, Cass R. Acordos Constitucionais sem Teorias Constitucionais. Tradução de Diego Werneck Arguelhes e Pedro Jimenez Cantisano. Revista de Direito Administrativo, Rio de Janeiro, v. 246, p. 79-94, set. 2007. Disponível em: http://bibliotecadigital.fgv.br/ojs/index.php/rda/article/view/41651/40827. Acesso em: 17 jul. 2021.

SUNSTEIN, Cass R. Beyond judicial minimalism. Public Law \& Legal Theory Working Paper, Chicago, n. 237, set. 2008. Disponível em: http://chicagounbound.uchicago.edu/cgi/viewcontent.cgi?article=1041\&context=publi c_law_and_legal_theory. Acesso em: 20 abr. 2021.

SUNSTEIN, Cass R. Constitutional personae. New York: Oxford University Press, 2015.

SUNSTEIN, Cass R. How changes happens. Cambridge: MIT Press, 2019.

SUNSTEIN, Cass R. Impeachment: a citizen's guide. London: Penguin Books, 2019.

SUNSTEIN, Cass R. Incompletely theorized agreements commentary. Harvard Law Review, Cambridge, n. 108, p. 1733-1772, 1994. Disponível em: 
http://chicagounbound.uchicago.edu/cgi/viewcontent.cgi?article=12308\&context=jour nal_articles. Acesso em: 20 abr. 2021.

SUNSTEIN, Cass R. Incompletely theorized agreements in Constitutional Law. Public Law \& Legal Theory Working Paper, Chicago, n. 147, jan. 2007. Disponível em: http://chicagounbound.uchicago.edu/cgi/viewcontent.cgi?article=1149\&context=publi c_law_and_legal_theory. Acesso em: 20 abr. 2021.

SUNSTEIN, Cass R. Legal reasoning and political conflict. New York: Oxford University Press, 1996.

SUNSTEIN, Cass R. One case at a time: judicial minimalism on the Supreme Court. Massachusetts: Harvard University Press, 1999.

SUNSTEIN, Cass R. Radical in Robes: Why extreme right-wing courts are wrong for America. New York: Basic Books, 2005.

SUNSTEIN, Cass R. The world according to Star Wars. New York: Dey Street Books, 2016. 